\title{
PENGARUH KINESIOTAPPING TERHADAP PENURUNAN NYERI AKIBAT LOW BACK PAIN PADA IBU HAMIL TRIMESTER III DI RSKDIA PERTIWI MAKASSAR
}

\author{
Muh. Thahir \\ Jurusan Fisioterapi Politeknik Kesehatan Makassar \\ muh.thahir81@gmail.com
}

\begin{abstract}
ABSTRAK
Pada masa Ibu Hamil seiring dengan membesarnya uterus maka pusat gravitasi akan berpindah kearah depan sehingga ibu hamil harus menyusuaikan posisi berdirinya. Postur tubuh yang tidak tepat akan memaksa peregangan tambahan dan kelalahan pada tubuh, terutama pada bagian tulang belakang sehingga menyebabkan terjadinya sakit atau nyeri pada bagian punggung ibu hamil. Nyeri punggung bawah adalah nyeri yang dirasakan didaerah punggung bawah, dapat berupa nyeri local (inflamasi) maupun nyeri radikuler ataupun keduanya. Penelitian ini bersifat quasy eksperimen dengan rancangan penelitian one group pre test dan post test design. Sampel yang diambil sebanyak 20 orang berumur antara 18-35 tahun. Penelitian ini menggunakan pengukuran nyeri sebelum dan setelah pemberian kinesiotapping selama 6 kali perlakuan. Data dianalisis melalui uji wilcoxon. Instrumen tes yang digunakan pada penelitian ini adalah VAS untuk mengukur nyeri akibat low back pain pada ibu hamil trimester III di Rumah Sakit Khusus Daerah Ibu dan Anak (RSKDIA) Pertiwi Makassar. Hasil uji Wilcoxon diperoleh adanya perbedaan signifikan nilai nyeri sebelum dan sesudah pemberian kinesiotapping dengan nilai $p=0,000 \quad(\mathrm{p}<0,05)$. Dengan demikian dapat disimpulkan bahawa Penggunaan intervensi kinesiotapping dalam mengurangi nyeri pinggang bawah ibu hamil trimester III. Untuk disarankan kepada fisioterapis agar mengaplikasikan intervensi kinesiotapping pada ibu hamil trimester III yang mengalami nyeri pinggang bawah.
\end{abstract}

Kata Kunci : Kinesiotapping, nyeri, low back pain

\section{Pendahuluan}

Kehamilan adalah pertumbuhan dan perkembangan janin intrauterin dimulai sejak konsepsi dan berakhir sampai permulaan persalinan. Lamanya hamil normal adalah 280 hari ( 40 Minggu atau 9 bulan 7 hari ) dihitung dari hari pertama haid terakhir. Kehamilan dibagi menjadi tiga triwulan yaitu triwulan pertama dimulai dari konsepsi sampai 3 bulan , triwulan kedua dari bulan ke-4 sampai ke-6 , triwulan ketiga dari bulan ke-7 sampai bulan ke-9. Perubahan yang terjadi selama kehamilan akan menjadi keluhan bagi ibu hamil diantaranya adalah mual muntah pada awal kehamilan. Pada kehamilan lebih lanjut, muncul keluhan - keluhan seperti nyeri pinggang bawah, varices, wasir, dan nyeri pelvis, nyeri tulang iga, disfungsi simfisis pubis, carpal tunnel syndrome, dan inkontinensia stress (Na Pravikasari , 2014).

Perubahan pada sistem muskuloskeletal yang terjadi selama kehamilan termasuk

perubahan dalam postur, tulang belakang atau nyeri pinggang serta sebagai penguluran dari otot perut. Nyeri pinggang merupakan salah satu masa kehamilan menjelang bulan ke tujuh banyak wanita hamil mengalami nyeri pinggang bawah (Mafikasari dan Kartikasari, 2015).

Pada kehamilan trimester III, seiring membesarnya uterus dan penambahan berat badan maka pusat gravitasi akan berpindah kearah depan sehingga ibu hamil harus menyesuaikan posisi berdirinya. Postur tubuh yang tidak tepat akan memaksa peregangan tambahan dan kelelahan pada tubuh, terutama pada daerah punggung belakang. Nyeri pinggang bawah juga bisa disebabkan karena perubahan hormonal yang menimbulkan perubahan pada jaringan lunak penyangga dan penghubung sehingga menurunnya elastisitas dan fleksibilitas otot (Wahyuni dkk, 2015). 
Perubahan sendi juga dapat ikut berpengaruh pada perubahan postur ibu hamil, disini bisa terjadi kenaikan mobilitas dari sendi - sendi tubuh seperti: sendi sakrokoksigeal, sakroiliaka, dan pubis yang dapat menimbulkan rasa tidak nyaman di punggung terutama terjadi pada masa-masa akhir kehamilan (Mafikasari dan Kartikasari, 2015). Nyeri pinggang bawah dapat menimbulkan dampak negatif pada kualitas hidup ibu hamil karena terganggunya aktifitas fisik sehari-hari (Wahyuni dkk, 2015). Postur tubuh yang tidak tepat akan memaksa peregangan tambahan dan kelalahan pada tubuh, terutama pada bagian tulang belakang sehingga menyebabkan terjadinya sakit atau nyeri pada bagian punggung ibu hamil. Nyeri punggung bawah atau Low Back Pain (LBP) adalah ketidaknyamanan yang terjadi dibawah costa dan diatas bagian inferior gluteal. LBP akut terjadi di bawah enam minggu, LBP sub akut 6-12 minggu dan LPB kronis diatas 12 minggu. Dan setiap aktivitas yang dilakukan memberikan pembebanan pada daerah pinggang (lumbal). Lumbal menerima pembebanan sebesar $25 \%$ dari berat badan pada saat tidur terlentang, $100 \%$ pada saat berdiri dengan posisi tegak, $150 \%$ saat duduk dengan posisi membungkuk, $140 \%$ saat duduk tegak, dan $185 \%$ saat duduk membungkuk hal ini menyebabkan mudah terjadi nyeri pinggang bawah.

\section{Metode Penelitian}

Penelitian ini menggunaan metode Quasi Experiment, dengan rancangan penelitian one group pre test dan post test design. Penelitian dilaksanakan di RSKDIA Pertiwi Makassar pada bulan September Oktober 2017. Populasi penelitian ini adalah semua ibu hamil yang datang berobat ke poliklinik Fisioterapi sebanyak 35 orang. Sampel penelitian adalah pasien yang menderita nyeri pinggang bawah pada ibu hamil trimester III sebanyak 20 orang. Sampel diambil secara purposive sampling berdasarkan kriteria inklusif : penderita nyeri pinggang bawah akibat spasme otot, usia sampel 18 - 35 tahun, tidak kontra indikasi dengan pemberian kinesiotapping, dan bersedia menjadi responden. Dilakukan
Nyeri pinggang bawah merupakan nyeri yang terjadi didaerah pinggang berikut pantat yang disebabkan oleh berbagai faktor penyebab seperti ketegangan otot, proyeksi organ dalam ataupun karena kerusakan organ tertentu. Kerusakan salah satu jaringan tertentu pada manusia dapat menimbulkan nyeri seperti : kerusakan tulang, persendian, ligamen dan otot.

Berdasarkan observasi yang dilakukan di RSKDIA Pertiwi Makasar, sebagian besar ibu hamil trimester III mengalami low back pain. Kondisi ini bisa ditangani dengan menggunakan modalitas fisioterapi seperti kinesiotapping. Kinesiotaping digunakan untuk mengurangi nyeri atau rasa tidak nyaman dari kulit dan otot, membantu otot dalam pergerakan, mengalirkan endapan cairan limfatik dibawah kulit, membantu mengkoreksi misalnya ligament sendi (Sudarsono, 2014) Kinesiotaping pada LPB ibu hamil berguna dalam meningkatkan fasilitasi kerja otot, menstabilkan sendi, dan menormalkan tonus otot dan abnormalitas fascia dari sendi sehingga mengurangi low back pain pada kehamilan. Berdasarkan hal tersebut diatas peneliti tertarik untuk meneliti Apakah ada pengaruh kinesiotapping terhadap penurunan nyeri akibat low back pain pada ibu hamil trimester III di RSKDIA Pertiwi Makassar.

dengan cara mencatat identitas sampel dan selanjutnya melakukan pengukuran nyeri sebelum dan sesudah perlakuan. Pada tahap pelaksanaan setiap sampel diukur nyerinya. Data yang diperoleh dianalisis dengan menggunakan uji normalitas yang dilanjutkan dengan uji pengaruh. Pengolahan dan analisis data dengan menggunakan SPSS, kemudian disajikan dalam bentuk tabel dan narasi.

\section{Hasil dan Pembahasan}

Penelitian ini dilaksanakan di RSKDIA Pertiwi Makassar selama 1 (satu) bulan, mulai pada bulan September - Oktober 2017 dengan mengambil sampel sebanyak 20 ibu yang mengalami persalinan normal. Data diolah dan dianalisis disesuaikan dengan tujuan 
penelitian. Hasil analisis disajikan dalam

penjelasan tabel sebagai berikut:

bentuk tabel yang dilengkapi dengan

Tabel 1. Distribusi Kelompok Umur Wanita Hamil Trimester III di RSKDIA Pertiwi Makassar Tahun 2017

\begin{tabular}{|c|c|c|}
\hline $\begin{array}{c}\text { Kelompok Umur } \\
\text { (Tahun) }\end{array}$ & Frekuensi & Persentase \\
\hline $18-23$ & 3 & 15,0 \\
$24-29$ & 10 & 50,0 \\
$30-35$ & 7 & 35,0 \\
\hline Jumlah & $\mathbf{2 0}$ & $\mathbf{1 0 0 , 0}$ \\
\hline
\end{tabular}

Sumber : Data Primer, 2017

Tabel 1 menunjukkan bahwa Kelompok Umur Wanita Hamil Trimester III di RSKDIA Pertiwi yang terbanyak adalah kelompok umur 24-29 tahun sebanyak 10 orang ( 50\%) sedangkan yang paling sedikit adalah kelompok umur 18 - 23 sebanyak 3 orang (15\%).

Tabel 2 Distribusi Nilai VAS Pre test dan Post test

\begin{tabular}{|l|c|c|c|}
\hline Kondisi & Nilai Rerata & Standar Deviasi & $\mathrm{n}$ \\
\hline Pre test & 6,90 & 1,774 & \multirow{2}{*}{20} \\
\cline { 1 - 3 } Post test & 4,20 & 1,508 & \\
\hline Selisih & 2,70 & 2,003 & \\
\hline
\end{tabular}

Tabel diatas memperlihatkan nilai rerata pre test yaitu 6,90 dan nilai rerata post test yaitu 4,20 dengan selisih nilai rerata adalah 2,70 . Perubahan nilai rerata yang diperoleh menunjukkan adanya penurunan intensitas nyeri setelah diberikan Kinesiotapping. Hal ini menunjukkan bahwa pemberian Kinesiotapping dapat menghasilkan penurunan nyeri pada penderita nyeri pinggang bawah pada Wanita Hamil trimester III, dengan rata-rata penurunan sebesar 2,70.

Tabel 3. Hasil Analisis Uji Wilcoxon

\begin{tabular}{|c|c|c|c|c|c|c|c|c|c|}
\hline \multirow{2}{*}{ Kondisi } & \multirow{2}{*}{$\mathrm{N}$} & \multirow{2}{*}{ Mean } & \multirow{2}{*}{ SD } & \multirow{2}{*}{$\begin{array}{l}\text { Beda } \\
\text { Rerata }\end{array}$} & \multicolumn{3}{|c|}{ Ranks } & \multirow{2}{*}{ Z } & \multirow[b]{2}{*}{$\mathrm{p}$} \\
\hline & & & & & - Ranks & + Ranks & Ties & & \\
\hline Pre test & 20 & 6,90 & 1,774 & \multirow{2}{*}{2,70} & \multirow[b]{2}{*}{20} & \multirow[b]{2}{*}{0} & \multirow[b]{2}{*}{0} & \multirow[b]{2}{*}{$-3,954$} & \multirow[b]{2}{*}{0,000} \\
\hline Post test & 20 & 4,20 & 1,508 & & & & & & \\
\hline
\end{tabular}

Tabel diatas menunjukkan hasil Uji Wilcoxon yang terdiri dari nilai Ranks dan nilai $\mathrm{Z}$. Berdasarkan nilai ranks, diperoleh angka 20 pada negatif ranks yang berarti bahwa semua responden mengalami penurunan intensitas nyeri setelah diberikan Kinesiotaping. Kemudian dilihat dari nilai $\mathrm{Z}$ diperoleh nilai sebesar $-3,954$ dengan nilai $\mathrm{p}=0,000<0,05$ yang berarti bahwa ada perbedaan yang bermakna setelah diberikan perlakuan dengan penurunan sebesar 2,70. Hal ini menunjukkan bahwa pemberian Kinesiotaping dapat menghasilkan pengaruh yang bermakna terhadap penurunan nyeri pada penderita nyeri pinggang bawah pada Wanita Hamil trimester III. 
Hasil penelitian yang terlihat pada tabel 2 menunjukkan bahwa pemberian kinesiotaping dapat menghasilkan penurunan nyeri yang bermakna pada penderita nyeri pinggang bawah Wanita Hamil trimester III, dengan rata-rata penurunan nyeri sebesar 2,70. Nyeri pinggang bawah yang dengan pada Wanita Hamil disebabkan karena pembebanan di lumbal. Kondisi ini lama kelamaan akan menimbulkan spasme otot erector spine sehingga menghambat fungsional lumbal. Dengan demikian, problem nyeri dan spasme otot erector spine harus diatasi untuk mengembalikan fungsional lumbal. Berdasarkan analisis diatas, dengan menggunakan uji wilcoxon, diperoleh nilai $\mathrm{P}=0,000<0,05$ yang berarti bahwa ada pengaruh yang bermakna kinesiotapping terhadap penurunan intensitas nyeri. Hal inilah yang menghasilkan penurunan nyeri pada nyeri pinggang bawah yang dirasakan oleh ibu hamil trimester III. Dalam sebuah penelitian, kinesiotaping secara klinis akan meningkatkan kemampuan biolektrik otot dengan menggunakan electromyogaphy (EMG) setelah 24 jam pemasangan kinesiotaping dan akan menurun fungsinya setelah 4 hari pemakaian. Hal tersebut dapat menjelaskan bahwa pemberian kinesiotaping cukup sampai dengan tiga hari karena puncak pengaruh dari kinesiotaping setelah 24 jam akan memfasilitasi motor unit untuk dapat melakukan kontraksi dan setelah 72 jam tonus otot menurun dan nyeri yang dirasakan juga menurun, sehingga untuk mengurangi dari tonus otot yang berlebih disarankan pemasangan cukup sampai dengan 3 hari (Slupik, et al, 2007).

Kinesiotaping digunakan untuk mengurangi nyeri, meningkatkan Lingkup Gerak Sendi (LGS), Mensupport fungsi sendi, mengaktifasi sistem limfatik dan sistem endogen analgesic. Meningkatkan mikrosirkulasi dan efek fungsi otot (Kase, 2003). Fungsi kinesiotaping dalam mensupport otot adalah dengan cara : 1) Meningkatkan kontraksi otot di otot yang melemah, 2) menurunkan kelelahan otot, 3) menurunkan kontraksi dan pengeluran yang berlebihan pada otot, 4) menurunkan menurunkan kejang dan kemungkinan cidera pada otot, 5) meningkatkan Range of motion (ROM) dan 6) mengurangi nyeri. Kinesiotaping juga menghilangkan kepadatan cairan tubuh untuk dialirkan, yaitu dengan cara : 1) meningkatkan sirkulasi darah dan cairan lymphe, 2) mengurangi kelebihan panas dan cairan kimia dalam jaringan, 3) mengurangi peradangan, 4) mengurangi rasa abnormal dan nyeri pada kulit dan otot, 5) mengaktivasi system Endogenous analgesic, 6) mengaktivasi sistem spinal inhibitory, 6) mengaktivasi system descending inhibitory. Dalam hal memperbaiki masalah sendi kinesiotaping bekerja dengan cara memperbaiki alignment akibat dari spasm dan pemendekan otot, menormalkan tonus otot dan abnormalitas dari fascia dari sendi, meningkatkan Range of motion, dan mengurangi nyeri (Kase, 2003). Metode kinesiotaping dengan cara melalui aktivasi system saraf dan peredaran darah. Metode ini pada dasarnya berasal dari ilmukinesiologi, Kinesiotaping dapat digunakan diberbagai kondisi karena kemampuannya untuk mengurangi rasa sakit, mengurangi peradangan,mengendurkan otot, meningkatkan kinerja dan memfasilitasi rehabilitasi sementara yang mendukung otot-otot dalam gerak (Kase, 2005). Pemberian kinesiotaping dapat membantu menurunkan nyeri pada ibu hamil trimester III. Pada penelitian ini perlakuan berupa pemberian Kinesiotaping rutin dilakukan oleh peneliti sehingga semua responden mengalami penurunan nyeri pinggang bawah pada ibu hamil. Nilai aktualitas nyeri sebelum adalah 6,90 $\pm 1,174$ dan sesudah

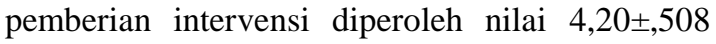
dengan selisih rata-rata 2,70 $\pm 2,003$. Hasil penelitian diperoleh nilai $p=0,004$ yang berarti bahwa ada pengaruh yang signifikan antara sebelum intervensi dan setelah intervensi. Hal ini sejalan dengan penelitian Wahyuni dan Eko Prabowo (2012). Dengan judul Manfaat Kinesiotaping Untuk Mengurangi Nyeri Pinggang Bawah Pada Kehamilan Trimester III dengan nilai $\mathrm{p}<0,05$ menunjukkan bahwa pemberiaan kinesiotaping bermanfaat bagi penurunan Nyeri Pinggang Bawah pada Ibu Hamil Trimester III. Dari hasil penelitian yang dilakukan peneliti didapatkan nilai $p(0,004)<0,05$ menunjukkan bahwa ada pengaruh yang signifikan setelah diberikan pemberian Kinesiotaping terhadap penurunan nyeri pinggang bawah pada ibu hamil trimester

\section{Kesimpulan}

Berdasarkan tujuan dan hasil penelitian diatas, maka dapat disimpulkan dibawah ini sebagai berikut : Pemberian Kinesiotapping dapat menghasilkan penurunan nyeri pada penderita 
nyeri pinggang bawah, dengan rata-rata penurunan nyeri sebesar 2,70; Nilai aktualitas nyeri sebelum pemberian intervensi adalah $6,90 \pm 1,774$ dan sesudah pemberian intervensi diperoleh nilai 4,20 $\pm 1,508$ dengan selisih rata-rata $2,70 \pm 2,003$; Disarankan kepada fisioterapis di Rumah Sakit atau di lahan praktek agar menggunakan intervensi DAFTAR PUSTAKA

Apley, A. Graham dan Louis Solomon. 1995. Buku Ajar Ortopedi Dan Fraktur Sistem Apley, Edisi ke tujuh. Winya Medika: Jakarta

Arikunto, Suharsimi, 1997, Prosedur Penelitian Suatu Pendekatan Praktek, Rineka Cipta Jakarta.

A.N. De Wolf, J. MA. Mens, 1994, Pemeriksaan Alat Penggerak Tubuh, Jakarta

Anas Tamsuri, 2006, Konsep dan Penetalaksanaan Nyeri, Penerbit Buku Kedokteran EGC, Jakarta.

Elizabeth C Wood, 1964, Massage Principles and Techniques, Second Edition, W.B. Sounders Company, Philadelphia, London.

Frances Tappan, 1988, Healing Massage Techniques, Appleton \& Lange, California.

Heru Purbo Kuntoro, Dkk, 1993, Sumber Fisis, Pusat Pendidikan Tenaga Kesehatan DEPKES RI, Jakarta.

Hasan M Iqbal, 2002, Pokok-Pokok Materi Metodologi Penelitian dan Aplikasinya, Ghalia Indonesia, Jakarta.

Hoppenfield, Stanley, Physical Examination of the Spine and Extremities, Appletion - century - New York.

J. Harjono, Retno Dumila, 2007, Perbedaan Pengaruh Perubahan Execise dalam Pencapaian Posisi Kepala
Kinesiotapping sebagai salah satu modalitas terpilih untuk kondisi nyeri pinggang bawah pada Wanita Hamil trimester III; Disarankan kepada fisioterapis di Rumah Sakit atau dilahan praktek agar memberikan edukasi kepada penderita nyeri pinggang bawah tentang kebiasaan mengggunakan postur yang baik saat bekerja atau beraktivitas. yang Simeteri Akibat Torticolis, Jurnal fisioterapi Indonusa, Vol. VII No. 1.

Kase,K., ,Wallis. J., Kase,T. 2003. Clinical Therapeutik Aplication Of The Kinesiotaping Methode. 2 Edition . Tokyo : Kense Kase

Pravikasari, Nila Analisa et al. 2014. Perbedaan Senam Hamil dan Teknik Akupresur Terhadap Penurunan Nyeri Punggung Bawah pada Ibu Hamil Trimester III. Thesis. Semarang: Program Pascasarjan Universitas.

Randolph M. Kessler, Darlene Hertling, 1983, Management of Common Musculosceletal Disorder. Physical Therapy Principles and Methods, Harprer \& Row Publishers Inc. East Washington Square, Philadelphia.

Mafikasari, Apriliyanti \& Kartikasari, Indah,Ratih. (2015). Posisi Tidur Dengan Kejadian Back Pain (Nyeri Punggung) Pada Ibu Hamil Trimester Iii Vol. 07, No.02

Schmenk, Barbara; Katrina Stibel. (2014). "Basic of Kinesiotaping". Jurnal Ohio Athletic. 20(1),19-21.

Sidharta, Priguna. 1984. Sakit Neuro Muskuloskeletal. PT.Dian Rakyat: Jakarta.

Sidharta, Priguna. 1985. Sakit Neuro Muskuloskeletal. PT.Dian Rakyat: Jakarta. 
Susan G. Salvo, 1999, Massage Therapy Principles and Practice, W. B. Sanders Company, Phyladelphia.

Susan J Garrison alih bahasa Anton Cahaya Widjaya, 2001, Dasar-dasar Terapi dan Rehabilitasi Fisik, Penerbit Hipokrates, Jakarta.

Soepeno, Bambang. 1997. Statistik Terapan. PT.Rineka Cipta: Jakarta

Soekidjo, Notoatmodjo. 1993. Metodologi Penelitian Kesehatan. PT. Rineka Cipta: Jakarta.

Sugiyono, 1997, Statistika dalam Penelitian, Alfabet, Bandung. 1999, Metode Penelitian Bisnis, CV Alfabeta, Bandung .

Sugiyono, 2006, Metode Penelitian Kualitatif, Kuantitatif dan $R \& D$, Penerbit Alfabeta Bandung.
Syafruddin Gaus, Manajemen Nyeri, Bagian Anestesiologi, Perawatan Intensif, dan Manajemen Nyeri, Fakultas Kedokteran Universitas Hasanuddin. Makassar.

Reduce Back and Pelvic Pain During and After Pregnancy. Journal Of Orthopaedic \& Sports Physical Therapy. Wahyuni \& Prabowo, Eko. (2012). Manfaat Kinesiotapping Untuk Mengurangi Nyeri Punggung Bawah Pada Kehamilan Trimester Ke-3. Jurnal Kesehatan.Vol. 5, No. 2,: 119 129.

Waluyo, Sugijanto, S. Indra Lesmana, 2004, Efektifitas Transverse Friction Terhadap Pengurangan Rasa Nyeri Pada Tennis Elbow, Majalah Fisioterapi Indonesia Vol 3 No 6. 